\title{
Longterm Safety and Efficacy of Subcutaneous Tocilizumab Monotherapy: Results from the 2-year Open-label Extension of the MUSASHI Study
}

\author{
Atsushi Ogata, Koichi Amano, Hiroaki Dobashi, Masayuki Inoo, Tomonori Ishii, \\ Tsuyoshi Kasama, Shinichi Kawai, Atsushi Kawakami, Tatsuya Koike, Hisaaki Miyahara, \\ Toshiaki Miyamoto, Yasuhiko Munakata, Akira Murasawa, Norihiro Nishimoto, \\ Noriyoshi Ogawa, Tomohiro Ojima, Hajime Sano, Kenrin Shi, Eisuke Shono, Eiichi Suematsu, \\ Hiroki Takahashi, Yoshiya Tanaka, Hiroshi Tsukamoto, and Akira Nomura, and the MUSASHI \\ Study Investigators
}

ABSTRACT. Objective. To evaluate the longterm safety and efficacy of subcutaneous tocilizumab (TCZ-SC) as monotherapy in patients with rheumatoid arthritis (RA).

Methods. Of 346 patients who received 24 weeks of double-blind treatment with either TCZ-SC monotherapy, $162 \mathrm{mg}$ every 2 weeks (q2w); or intravenous TCZ (TCZ-IV) monotherapy, $8 \mathrm{mg} / \mathrm{kg}$ every 4 weeks; 319 patients continued to receive TCZ-SC q2w in the 84-week open-label extension (OLE) of the MUSASHI study (JAPICCTI-101117). Efficacy, safety, and immunogenicity were evaluated for all patients treated with TCZ during 108 weeks.

Results. The proportions of patients who achieved American College of Rheumatology 20/50/70 responses, low disease activity [28-joint Disease Activity Score (DAS28) $\leq 3.2$ ], or remission (DAS28 $<2.6)$ at Week 24 were maintained until Week 108. The incidences of adverse events and serious adverse events were 498.3 and 16.9 per 100 patient-years (PY), respectively. The overall safety of TCZ-SC monotherapy was similar to that of TCZ-IV monotherapy. Rates of injection site reactions (ISR) through 108 weeks remained similar to rates through 24 weeks. ISR were mild and did not cause any patient withdrawals. No serious hypersensitivity events (including anaphylactic reactions) occurred. Anti-TCZ antibodies were present in $2.1 \%$ of patients treated with TCZ-SC monotherapy. Conclusion. TCZ-SC monotherapy maintained a favorable safety profile and consistent efficacy throughout the 108-week study. Like TCZ-IV, TCZ-SC could provide an additional treatment option for patients with RA. (First Release April 1 2015; J Rheumatol 2015;42:799-809; doi:10.3899/ jrheum.140665)

Key Indexing Terms: RHEUMATOID ARTHRITIS SUBCUTANEOUS INJECTIONS

\section{HUMANIZED MONOCLONAL ANTIBODIES} ADVERSE EVENTS

From the Department of Respiratory Medicine, Allergy and Rheumatic Disease, Osaka University Graduate School of Medicine and Department of Immunopathology, WPI Immunology Frontier Research Center, Osaka University, Osaka; Department of Rheumatology and Clinical Immunology, Saitama Medical Center, Saitama Medical University,

Saitama; Department of Internal Medicine, Division of Endocrinology and Metabolism, Hematology, Rheumatology and Respiratory Medicine,

Faculty of Medicine, Kagawa University; Department of Rheumatology,

Utazu-Hama Clinic, Kagawa; Department of Hematology and

Rheumatology, Tohoku University Hospital, Sendai; Division of

Rheumatology, Department of Medicine, Showa University School of

Medicine; Division of Rheumatology, Department of Internal Medicine,

Toho University School of Medicine, Tokyo; Unit of Translational

Medicine, Department of Immunology and Rheumatology, Nagasaki

University Graduate School of Biomedical Sciences, Nagasaki;

Department of Rheumatosurgery, Osaka City University, Graduate School

of Medicine, Osaka; Department of Internal Medicine and Rheumatology,

National Hospital Organization Kyushu Medical Center, Fukuoka;

Department of Rheumatology, Seirei Hamamatsu General Hospital,

Shizuoka; Munakata Yasuhiko Clinic, Miyagi; Department of

Rheumatology, Niigata Rheumatic Center, Niigata; Osaka Rheumatology

Clinic, Osaka; Third Department of Internal Medicine, Hamamatsu
University School of Medicine, Shizuoka; Department of Orthopedic Surgery, Fukui General Hospital, Fukui; Division of Rheumatology, Department of Internal Medicine, Hyogo College of Medicine, Hyogo; Department of Orthopedic Surgery, Osaka University Graduate School of Medicine, Osaka; Shono Rheumatology Clinic, Fukuoka; First Department of Internal Medicine, Sapporo Medical University School of Medicine, Hokkaido; The First Department of Internal Medicine, School of Medicine, University of Occupational and Environmental Health, Fukuoka; Department of Medicine and Biosystemic Science, Kyushu University Graduate School of Medical Sciences, Fukuoka; Chugai Pharmaceutical Co. Ltd., Tokyo, Japan.

Funded by Chugai Pharmaceutical Co. Ltd. Support for third-party writing assistance for this manuscript, provided by Denise Kenski, PhD, of Health Interactions, was supported by Genentech Inc. A. Ogata has received consulting fees, speaking fees, and/or honoraria from Chugai Pharmaceutical. N. Nishimoto has received consulting fees, speaking fees, and patent or license-related income from Chugai Pharmaceutical. $Y$. Tanaka has received speaking fees from Chugai Pharmaceutical. A. Nomura is employed by Chugai Pharmaceutical.

A. Ogata, MD, PhD, Osaka University Graduate School of Medicine and Osaka University; K. Amano, MD, PhD, Saitama Medical Centre, Saitama

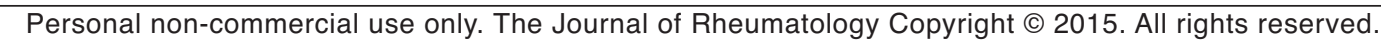


Medical University; H. Dobashi, MD, PhD, Kagawa University; M. Inoo, MD, PhD, Utazu-Hama Clinic; T. Ishii, MD, PhD, Tohoku University Hospital; T. Kasama, MD, PhD, Showa University School of Medicine; S. Kawai, MD, PhD, Toho University School of Medicine; A. Kawakami, MD, PhD, Nagasaki University Graduate School of Biomedical Sciences; T. Koike, MD, PhD, Osaka City University Medical School; H. Miyahara, MD, PhD, National Hospital Organization Kyushu Medical Center; T. Miyamoto, MD, Seirei Hamamatsu General Hospital; Y. Munakata, $M D, P h D$, Munakata Yasuhiko Clinic; A. Murasawa, MD, PhD, Niigata Rheumatic Center; N. Nishimoto, MD, PhD, Osaka Rheumatology Clinic; N. Ogawa, MD, PhD, Hamamatsu University School of Medicine; T. Ojima, MD, PhD, Fukui General Hospital; H. Sano, MD, PhD, Hyogo College of Medicine; K. Shi, MD, PhD, Osaka University Graduate School of Medicine; E. Shono, MD, PhD, Shono Rheumatology Clinic; E. Suematsu, MD, National Hospital Organization Kyushu Medical Center; K.H. Takahashi, MD, PhD, Sapporo Medical University School of Medicine; Y. Tanaka, MD, PhD, University of Occupation and Environmental Health; H. Tsukamoto, MD, PhD, Kyushu University Graduate School of Medical Sciences; A. Nomura, MSc, Chugai Pharmaceutical.

Address correspondence to Dr. A. Ogata, Department of Respiratory Medicine, Allergy and Rheumatic Disease, Osaka University Graduate School of Medicine, 2-2, Yamadaoka, Suita, Osaka 565-0871, Japan. E-mail: ogata@imed3.med.osaka-u.ac.jp

Accepted for publication January 27, 2015.

Rheumatoid arthritis (RA) is a chronic, progressive, systemic autoimmune disease characterized by synovitis leading to damage of diarthrodial joints. For patients with an insufficient response to disease-modifying antirheumatic drugs (DMARD), the American College of Rheumatology (ACR) and European League Against Rheumatism (EULAR) guidelines recommend treatment with biologic agents ${ }^{1,2}$. Biologics have become available that target key cytokines in the pathogenesis of RA, including inhibitors of tumor necrosis factor (TNF)- $\alpha$, interleukin 6 (IL-6), IL-1, CD20, and cytotoxic T lymphocyte antigen $4^{3}$. These biologics have demonstrated efficacy in patients with RA, yet differences in the route of administration, frequency of dosing, and safety profile can affect patient satisfaction and compliance $e^{4,5,6}$. For a fuller assessment of the longterm risk/benefit profiles of these therapeutics in patients with RA, it is necessary to evaluate their safety and efficacy over a significant period of time.

Tocilizumab (TCZ) is a humanized monoclonal antibody directed against the IL-6 receptor. Upon binding to the IL-6 receptor, TCZ blocks IL- 6 receptor signaling and subsequent proinflammatory activities ${ }^{7}$. The efficacy and safety profiles of TCZ were comparable among phase III studies and were associated with a risk/benefit ratio that supported its use in patients with RA R, $^{8,10,11,12,13,14}$. TCZ by intravenous (IV) administration has been approved in more than 100 countries for the treatment of patients with RA. TCZ by subcutaneous (SC) administration was recently approved in Japan and the United States for patients with RA. The TCZ-SC formulation has a shorter infusion time compared with TCZ-IV, does not require an infusion facility for administration, and can be administered at home by self-injection.

The initial efficacy, safety, and pharmacokinetics of TCZ-SC monotherapy (TCZ-SC-mono) were evaluated in an open-label phase I/II study conducted in Japan at 3 doses [81 mg every 2 weeks (q2w), $162 \mathrm{mg} \mathrm{q} 2 \mathrm{w}$, and $162 \mathrm{mg}$ weekly (qw)] over 6 months ${ }^{15}$. The MUSASHI study (Multicenter Double-Blind Study of Actemra Subcutaneous Injection in Patients Having Rheumatoid Arthritis to Verify Noninferiority Against Intravenous Infusion) a multicenter, parallel-group, double-blind, 24-week phase III trial was conducted to compare the efficacy and safety of TCZ-SC-mono $162 \mathrm{mg}$ $\mathrm{q} 2 \mathrm{w}$ and TCZ-IV-mono $8 \mathrm{mg} / \mathrm{kg}$ every 4 weeks (q4w) in Japanese patients with RA. The study met its primary endpoint by demonstrating the noninferiority of TCZ-SC-mono to TCZ-IV-mono regarding ACR20 response rates at Week $24^{16}$. Because body mass index (BMI) can affect treatment responses, we investigated the effect of body weight-related adjustment of TCZ-SC administration on efficacy.

In the present study, an 84-week open-label extension (OLE), we evaluated the longterm efficacy and safety profile of TCZ-SC-mono $162 \mathrm{mg} \mathrm{q} 2 \mathrm{w}$ in patients with RA. In addition, we evaluated adjustment of the administration interval.

\section{MATERIALS AND METHODS}

Study design. This was a 108-week, randomized, double-dummy, parallel-group phase III trial with a double-blind period of 24 weeks (MUSASHI) followed by an OLE period of 84 weeks in Japanese patients with RA (JAPICCTI-101117). The protocol was approved by the Japanese Ministry of Health, Labor, and Welfare and the institutional review boards at all study sites, and the study was completed in accordance with the ethical standards of the current version of the 1964 Declaration of Helsinki. At enrollment in the double-blind study, all patients provided signed informed consent.

At the start of the double-blind period, patients were randomized 1:1 into 2 groups: TCZ-SC-mono $162 \mathrm{mg}$ q2w plus placebo-TCZ-IV q4w or TCZ-IV-mono $8 \mathrm{mg} / \mathrm{kg} \mathrm{q} 4 \mathrm{w}$ plus placebo-TCZ-SC q2w. After 24 weeks, patients received open-label TCZ-SC-mono $162 \mathrm{mg}$ q2w for 84 weeks. The eligibility criteria for participation in this study have been described ${ }^{16}$. In brief, patients 20 to 70 years of age with RA for $\geq 6$ months (1987 ACR criteria) who had an inadequate response to any synthetic DMARD, biologic DMARD, or immunosuppressant were included. The first dose of TCZ-SC-mono in the OLE was administered at Week 24 in the double-blind period. During the OLE, if the investigator assessed for lack of efficacy as defined by not achieving a $>20 \%$ improvement in swollen or tender joint count compared with baseline (start of the double-blind period) and a C-reactive protein (CRP) level $>0.3 \mathrm{mg} / \mathrm{dl}$ in the last laboratory test, the principal investigator could shorten the dosing interval to qw. If patients maintained low disease activity, as indicated by a 28 -joint Disease Activity Score using erythrocyte sedimentation rate (DAS28-ESR) of $\leq 3.2$ for 24 weeks, the principal investigator could extend the dosing interval to every 3 weeks (q3w).

Safety and immunogenicity assessment. Safety was evaluated through both the double-blind period and the OLE period for all patients who received $\geq$ 1 dose of TCZ irrespective of their treatment group during the double-blind period. Adverse events (AE) and serious AE (SAE) were classified using the Medical Dictionary for Regulatory Activities (MedDRA, version 13.0). An $\mathrm{AE}$ was considered to be a treatment-emergent $\mathrm{AE}$ if it occurred during the study or if the severity of a preexisting condition increased during the study. All events occurring at the injection site, as judged by the investigator, were classified as injection site reactions (ISR). An SAE was any event that resulted in death, was life-threatening, required hospitalization or medical or surgical intervention, or resulted in a persistent or significant disability, cancer, or congenital defect.

Personal non-commercial use only. The Journal of Rheumatology Copyright @ $\odot$ 2015. All rights reserved 
Anti-TCZ antibodies were measured $\mathrm{q} 4 \mathrm{w}$ during the double-blind period and then every 12 weeks in the OLE period using the ELISA method described previously ${ }^{17}$.

Pharmacokinetics. Serum TCZ concentration was measured every 12 weeks throughout the OLE period as described ${ }^{18}$. The below limit of quantitation (BLQ) of TCZ was $0.1 \mu \mathrm{g} / \mathrm{ml}$.

Efficacy assessment. Efficacy was evaluated for patients who received $\geq 1$ dose of TCZ during the 108 weeks of treatment. Disease activity in both the double-blind and the OLE periods was monitored every 4 weeks. Disease activity was evaluated by DAS28-ESR, ACR core set, and Clinical Disease Activity Index (CDAI). The percentages of patients with low disease activity $(\mathrm{DAS} 28-\mathrm{ESR} \leq 3.2)$, remission $(\mathrm{DAS} 28-\mathrm{ESR}<2.6)$, CDAI remission $(\mathrm{CDAI} \leq 2.8)$, and EULAR response were also calculated.

Statistical analysis. Baseline demographic data and clinical characteristics were analyzed descriptively for patients who received $\geq 1$ dose of TCZ during the double-blind period. Safety was evaluated for all patients who received $\geq 1$ dose of $\mathrm{TCZ}$ during the double-blind period, and $\mathrm{AE}$ were included in the analyses if they occurred in the TCZ-IV group during the double-blind period. ISR were evaluated as events that occurred after the first TCZ-SC dose for patients who received $\geq 1$ dose of TCZ-SC-mono. Efficacy was evaluated for all patients who received $\geq 1$ dose of TCZ during the double-blind period, irrespective of their treatment group during the period. For missing data, nonresponder imputation was applied to ACR response data (ACR20/50/70), DAS28 remission, and CDAI remission, while last observation carried forward (LOCF) was applied to continuous data (DAS28). These efficacy data were expressed with $95 \%$ CI. For the patients who changed dosing intervals, safety was evaluated using the incidence rate during the dose-changing period, and efficacy was evaluated as trends over time after changing the dosing interval. The study design was not initially powered for the posthoc analyses presented here.

\section{RESULTS}

Patient disposition. Of 346 patients who were treated in 24 weeks of double-blind treatment with either TCZ-SC-mono,
$162 \mathrm{mg} \mathrm{q} 2 \mathrm{w}$, or TCZ-IV-mono, $8 \mathrm{mg} / \mathrm{kg} \mathrm{q} 4 \mathrm{w}$, a total of 319 patients $(92.2 \%)$ continued to receive TCZ-SC q2w in the OLE (Figure 1). Exposure to TCZ-SC-mono was 561.71 patient-years (PY) over the 108 weeks, including the 24-week double-blind period and the following 84-week OLE period. A total of 278 patients $(80.3 \%)$ remained in the study after 108 weeks. AE were the most common reason for withdrawal from the study over the 108 weeks (Figure 2); there was no clustering of $\mathrm{AE}$ that were predominantly responsible for patient withdrawals.

Baseline demographics, disease characteristics, and RA treatment at entry into the double-blind study have been published $^{16}$. Patient baseline characteristics were as follows: mean \pm SD body weight $54.0 \pm 9.5 \mathrm{~kg}$, mean \pm SD disease duration $7.7 \pm 7.4$ years, percentage of patients with a history of TNF- $\alpha$ inhibitor use $22.0 \%$, and the percentage of patients using steroids at baseline $63.3 \%$ (Table 1). DAS28-ESR (LOCF, $\mathrm{n}=346$ ) improved from $6.21 \pm 0.90$ at Week 0 to 2.76 \pm 1.36 at Week 24 and serum IL-6 level changed from $35.4 \pm$ $43.6 \mathrm{pg} / \mathrm{ml}$ at Week 0 to $49.7 \pm 69.6 \mathrm{pg} / \mathrm{ml}$ at Week 24 .

Safety. The incidence of AE and SAE were 498.3 per $100 \mathrm{PY}$ and 16.9 per $100 \mathrm{PY}$, respectively. The safety profile of TCZ-SC-mono remained stable over time. The most frequently reported $\mathrm{AE}$ were nasopharyngitis, pharyngitis, upper respiratory infection, hypercholesterolemia, and injection site erythema (Table 2). All discontinuations and the subsets of discontinuations due to AE are presented in a Kaplan-Meier plot (Figure 2). Withdrawal owing to AE occurred at the same frequency throughout the trial, and the

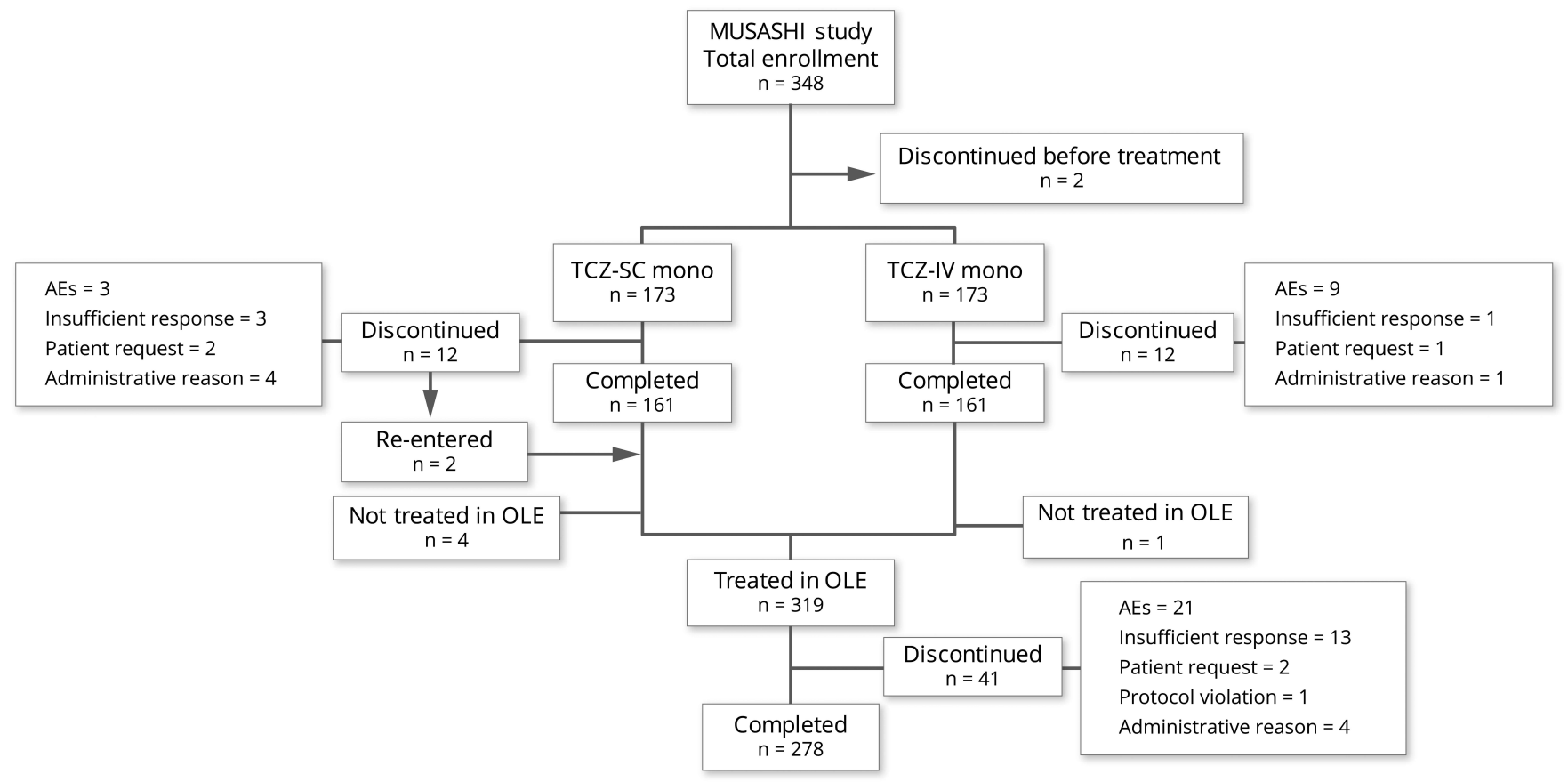

Figure 1. Patient disposition. AE: adverse event; OLE: open-label extension; TCZ-IV-mono: intravenous tocilizumab monotherapy; TCZ-SC-mono: subcutaneous TCZ monotherapy.

Personal non-commercial use only. The Journal of Rheumatology Copyright (C) 2015. All rights reserved. 


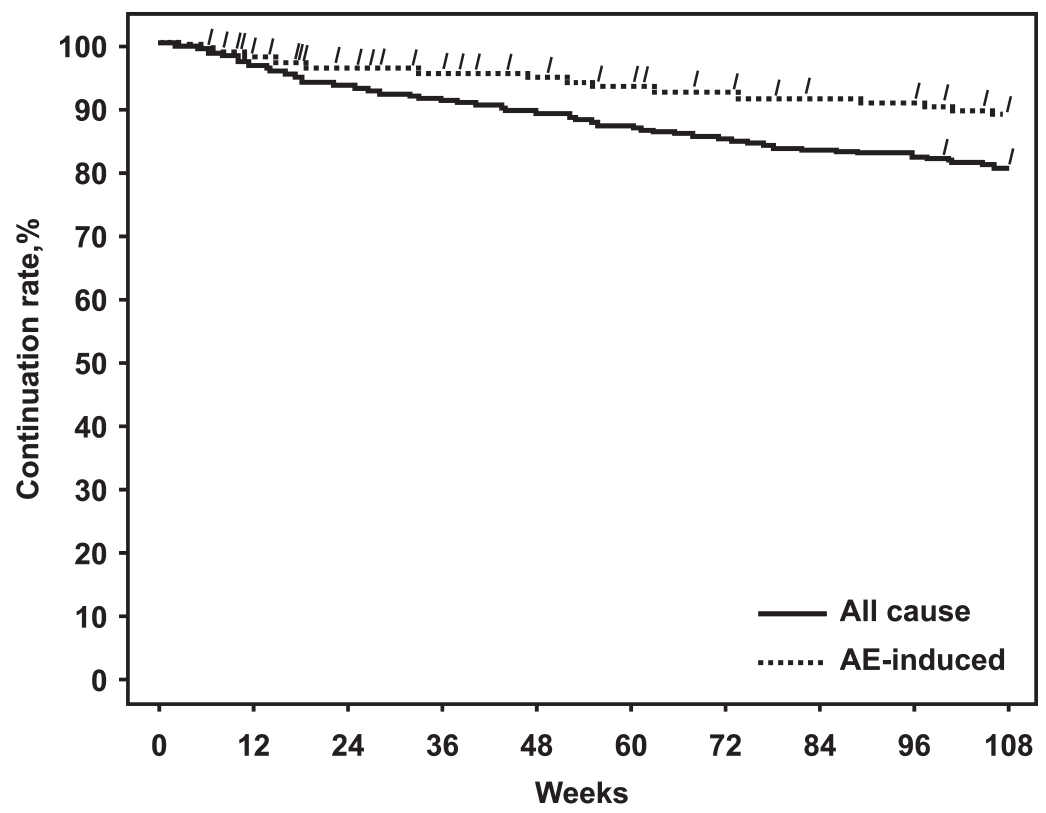

Figure 2. Kaplan-Meier plot of discontinuations over 108 weeks. AE: adverse events.

Table 1. Demographics and characteristics at baseline. Data are presented as $\mathrm{n}(\%)$ or mean $\pm \mathrm{SD}$.

\begin{tabular}{lc}
\hline Characteristics & Baseline, $\mathrm{n}=346$ \\
\hline Female & $287(82.9)$ \\
$\quad$ Age, yrs & $52.5 \pm 12.4$ \\
Body weight, $\mathrm{kg}$ & $54.0 \pm 9.5$ \\
$\quad$ Disease duration, yrs & $7.7 \pm 7.4$ \\
Steinbrocker functional class & \\
I & $48(13.9)$ \\
II & $253(73.1)$ \\
III & $45(13.0)$ \\
Steinbrocker stage & \\
I & $29(8.4)$ \\
II & $129(37.3)$ \\
III & $97(28.0)$ \\
IV & $91(26.3)$ \\
RF-positive & $283(81.8)$ \\
Anti-CCP antibody-positive & $312(90.2)$ \\
IL-6, pg/ml & $35.4 \pm 43.6$ \\
DAS28-ESR & $6.2 \pm 0.9$ \\
Swollen joint count (66 joints) & $14.3 \pm 7.5$ \\
Tender joint count (68 joints) & $18.3 \pm 9.6$ \\
Patient global VAS, mm & $57.4 \pm 24.0$ \\
CRP, mg/dl & $2.2 \pm 2.2$ \\
ESR, mm/h & $49.4 \pm 24.4$ \\
Previous treatment with TNF inhibitor & $76(22.0)$ \\
Previous treatment with methotrexate & $333(96.2)$ \\
Oral corticosteroid treatment & $219(63.3)$ \\
\hline CCP cyclic citmlinated &
\end{tabular}

CCP: cyclic citrullinated peptide; CRP: C-reactive protein; ESR: erythrocyte sedimentation rate; DAS28-ESR: 28-joint Disease Activity Score using ESR; IL-6: interleukin 6 (normal range: $<4.0 \mathrm{pg} / \mathrm{ml}$ ); RF: rheumatoid factor; TNF: tumor necrosis factor; VAS: visual analog scale.
Table 2. Frequently reported treatment-emergent adverse events ( $\geq 2 \%)$.

\begin{tabular}{|c|c|}
\hline Adverse Event & $\%$ of Patients \\
\hline Nasopharyngitis & 46.5 \\
\hline Upper respiratory tract infections & 21.1 \\
\hline Blood cholesterol increased & 20.2 \\
\hline Low-density lipoprotein cholesterol increased & 18.5 \\
\hline Pharyngitis & 15.0 \\
\hline Blood triglycerides increased & 13.3 \\
\hline ALT increased & 13.0 \\
\hline Stomatitis & 11.3 \\
\hline Eczema & 11.3 \\
\hline$\gamma$-GT increased & 10.7 \\
\hline Injection site erythema & 10.7 \\
\hline White blood cells decreased & 10.7 \\
\hline
\end{tabular}

ALT: alanine aminotransferase; $\gamma$-GT: $\gamma$-glutamyl transpeptidase.

gradient of the Kaplan-Meier plot was constant over time. In the 24-week double-blind period, 3.5\% (12 of 346) of patients withdrew because of AE. Three patients did not enter the OLE because of AE; in the 84-week OLE period, 6.6\% (21 of 319) withdrew because of AE. The most common reasons for AE-related withdrawal were infections, which included shingles $(0.9 \%)$, pneumonia $(0.9 \%)$, and atypical mycobacterial infection $(0.9 \%)$.

Rates of SAE were stable over time (Table 3). A total of $108 \mathrm{SAE}$ were reported during the study; 26 resulted in discontinuation and 1 resulted in death due to gastric cancer with disseminated intravascular coagulation that developed in the OLE period. The most common SAE were infections, 
Table 3. Safety summary. Multiple occurrences of the same adverse event (AE) in 1 individual were counted only once.

\begin{tabular}{|c|c|c|c|c|}
\hline \multirow[b]{2}{*}{ Total exposure period, $\mathrm{PY}$} & \multicolumn{4}{|c|}{ Week } \\
\hline & $\begin{array}{c}0-24, n=346 \\
154.7\end{array}$ & $\begin{array}{c}24-48, n=319 \\
144.6\end{array}$ & $\begin{array}{c}48-72, \mathrm{n}=309 \\
138.2\end{array}$ & $\begin{array}{c}72-108, n=294 \\
201.3\end{array}$ \\
\hline \multicolumn{5}{|l|}{$\mathrm{AE}$} \\
\hline Total no. patients & 311 & 249 & 233 & 235 \\
\hline Total no. AE (events/100 PY) & $1148(742.0)$ & $724(500.8)$ & $593(429.2)$ & $719(357.2)$ \\
\hline (95\% CI for rate) & $(699.7-786.2)$ & $(465.0-538.6)$ & $(395.4-465.2)$ & $(331.6-384.3)$ \\
\hline \multicolumn{5}{|l|}{ Infections } \\
\hline Total no. patients & 150 & 139 & 130 & 158 \\
\hline Total no. (events/100 PY) & $228(147.4)$ & $206(142.5)$ & $174(125.9)$ & $276(137.1)$ \\
\hline (95\% CI for rate) & $(128.9-167.8)$ & $(123.7-163.3)$ & $(107.9-146.1)$ & $(121.4-154.3)$ \\
\hline \multicolumn{5}{|l|}{ Malignancy } \\
\hline Total no. patients & 24 & 23 & 20 & 22 \\
\hline Total no. (events/100 PY) & $32(20.7)$ & $25(17.3)$ & $24(17.4)$ & $27(13.4)$ \\
\hline (95\% CI for rate) & $(14.2-29.2)$ & $(11.2-25.5)$ & $(11.1-25.9)$ & $(8.8-19.5)$ \\
\hline \multicolumn{5}{|l|}{ Serious infections } \\
\hline Total no. patients & 7 & 10 & 6 & 10 \\
\hline Total no. (events/100 PY) & $7(4.52)$ & $10(6.92)$ & $6(4.34)$ & $11(5.46)$ \\
\hline ( $95 \%$ CI for rate) & $(1.82-9.32)$ & $(3.32-12.72)$ & $(1.59-9.45)$ & $(2.73-9.78)$ \\
\hline
\end{tabular}

PY: patient-years.

which included pneumonia, shingles, gastroenteritis, and cellulitis (Table 4). Thirty patients (34 AE; 5.3 events per 100 PY) reported serious infections over 108 weeks. Four malignancies were reported during the OLE. Times to the event and resolution were ovarian cancer (64 weeks, unresolved), colon cancer (97 weeks, unresolved), gastric cancer (61 weeks, death), and breast carcinoma in situ (67 weeks, unresolved). In addition, 1 patient developed a lumbar facet cyst (3 weeks, resolving).

ISR occurred in $13.2 \%$ of patients (44 of 333) treated with TCZ-SC monotherapy over 108 weeks. The most common were erythema (32 patients), pruritus (8 patients), hemorrhage ( 7 patients), and swelling (5 patients). All ISR were mild, and no cases resulted in withdrawal from the study. The incidence of systemic injection reactions from TCZ-SC-mono was $4.8 \%$ (16 of 333 patients). The most common injection reactions were headache (5 patients) and fever (3 patients). No serious hypersensitivity events, including anaphylactic reactions, were reported.

The number of patients who experienced elevations in lipid levels and liver function tests during 108 weeks is shown in Table 5. The number of patients who experienced a worst value in liver transaminase [aspartate aminotransferase and alanine aminotransferase (ALT)] is also shown in Table 5 . The proportion of patients who experienced a grade 3 or grade 4 decrease in neutrophils $\left(<1000\right.$ cells $\left./ \mathrm{mm}^{3}\right)$ was $5.5 \%$ (19 of 346 patients) through Week 108.
Immunogenicity. The proportion of patients who received TCZ-SC-mono who tested positive for anti-TCZ antibodies in the screening and confirmation assays was $2.1 \%$ ( 7 of 333). Of these 7 patients, anti-TCZ antibodies appeared before Week 12 in 5 patients. Anti-TCZ antibodies were detected after switching from TCZ-IV-mono to TCZ-SC-mono in only 1 patient. No patients who developed anti-TCZ antibodies experienced a lack of efficacy or a decrease in serum TCZ concentration after developing anti-TCZ antibodies. There was no correlation between anti-TCZ antibodies and ISR. No ISR or anaphylactic reactions were observed in patients who tested positive for anti-TCZ antibodies.

Efficacy. ACR20, ACR50, and ACR70 response rates, CDAI remission, and DAS28 remission were analyzed by nonresponder imputation, and DAS28-ESR was analyzed by LOCF. There was similar efficacy among patients who received TCZ-IV-mono or TCZ-SC-mono in the double-blind period (weeks 0-24; Figure 3). At Week 108, the response rates $(95 \% \mathrm{CI})$ for the TCZ-IV-mono and TCZ-SC-mono groups were ACR20 of $77.5 \%(71.2,83.7)$ and $71.7 \%(65.0$, 78.4), ACR50 of $65.3 \%(58.2,72.4)$ and $64.7 \%(57.6,71.9)$, ACR70 of $49.1 \%(41.7,56.6)$ and $50.3 \%(42.8,57.7)$, CDAI remission of $39.9 \%(32.6,47.2)$ and $37.0 \%(29.8,44.2)$, DAS28 remission of $64.7 \%(57.6,71.9)$ and $63.6 \%(56.4$, $70.8)$, and DAS28-ESR of $2.36(2.14,2.57)$ and $2.34(2.11$, 2.57 ), respectively. In total, the proportions of patients who

Personal non-commercial use only. The Journal of Rheumatology Copyright $\subset$ 2015. All rights reserved. 
Table 4. Summary of serious adverse events (SAE) by body system. Data are presented as n (\%), except where indicated. Multiple occurrences of the same AE in 1 individual were counted only once.

\begin{tabular}{lc}
\hline Body System or AE & $\mathrm{n}=346$ \\
\hline Total exposure period, PY & 639.0 \\
All body systems & \\
$\quad$ Total no. patients with $\geq 1$ SAE & 77 \\
$\quad$ Total no. SAE & $108(16.9)$ \\
Infections and infestations & \\
$\quad$ Total no. SAE, PY & $34(5.3)$ \\
$\quad$ Pneumonia & $10(1.6)$ \\
Shingles & $6(0.9)$ \\
$\quad$ Gastroenteritis & $3(0.5)$ \\
Cellulitis & $3(0.5)$ \\
Musculoskeletal and connective tissue disorders & \\
$\quad$ Total no. SAE, PY & $17(2.7)$ \\
$\quad$ Joint destruction & $5(0.8)$ \\
Foot deformity & $3(0.5)$ \\
Synovitis & $2(0.3)$ \\
Osteoarthritis & $2(0.3)$ \\
Gastrointestinal problems & \\
Total no. SAE, PY & $14(2.2)$ \\
Colon polyps & $5(0.8)$ \\
Injury, poisoning, and procedural complications & \\
Total no. SAE, PY & $9(1.4)$ \\
Joint dislocation & $2(0.3)$ \\
Vertebral compression fracture & $2(0.3)$ \\
Tendon rupture & $2(0.3)$ \\
Respiratory, thoracic, and mediastinal disorders & \\
$\quad$ Total no. SAE, PY & $6(0.9)$ \\
Asthma & $2(0.3)$ \\
Cataract & $2(0.3)$ \\
\hline
\end{tabular}

$\mathrm{AE} \geq 0.2$ per $100 \mathrm{PY}$ in total (safety). AE: adverse event; PY: patient-year.

achieved ACR20/50/70 (95\% CI) responses were 79.2\% $(74.9,83.5) / 61.6 \%(56.4,66.7) / 37.3 \%(32.2,42.4)$ at Week $24,80.6 \%(76.5,84.8) / 65.0 \%(60.0,70.1) / 44.8 \%(39.6,50.0)$ at Week 48 , and $74.6 \%(70.0,79.2) / 65.0 \%(60.0,70.1) / 49.7 \%$ $(44.4,55.0)$ at Week 108, respectively (Figure 4A). The DAS28-ESR (mean \pm SD) values in patients who received TCZ-SC-mono were $6.21 \pm 0.90$ at baseline, $2.76 \pm 1.36$ at Week 24, $2.61 \pm 1.39$ at Week 48, and $2.35 \pm 1.49$ at Week 108 (Figure 4B). The proportion of patients who achieved DAS28-ESR remission or low disease activity $(95 \% \mathrm{CI})$ also improved over time, from $52.3 \%(47.0,57.6)$ and $68.5 \%$ $(63.6,73.4)$ at Week 24 to $64.2 \%(59.1,69.2)$ and $71.1 \%$ $(66.3,75.9)$ at Week 108, respectively (Figure 4C). The proportion of patients who achieved CDAI remission also improved over time, from $18.5 \%$ at Week 24 to $38.4 \%$ at Week 108 (Figure 4C). The proportion of patients who received TCZ-SC-mono and achieved a good EULAR response at Week $24(68.5 \%)$ and maintained the response through Week 108 was $70.8 \%$.

The proportion of patients who withdrew owing to lack of efficacy remained stable, from $1.2 \%$ at Week 24 to $4.9 \%$ at Week 108.
Table 5. Laboratory values of lipid and liver function.

Change Observed $\quad \begin{gathered}\text { No. Patients Treated with TCZ-SC-mono, } \\ \text { total }=346\end{gathered}$

Shift in total cholesterol from baseline $<200 \mathrm{mg} / \mathrm{dl}$ to last observed value over Week 108

$\begin{array}{lc}N & 266 \\ <200 & 132 \\ \geq 200 \text { to }<240 & 102 \\ \geq 240 & 32\end{array}$

Shift in HDL cholesterol from baseline $<40 \mathrm{mg} / \mathrm{dl}$ to last observed value over Week 108

$\begin{array}{lr}\mathrm{N} & 43 \\ <40 & 12 \\ \geq 40 \text { to }<60 & 26 \\ \geq 60 & 5\end{array}$

Shift in LDL cholesterol from baseline $<100 \mathrm{mg} / \mathrm{dl}$ to last observed value over Week 108

$\begin{array}{lc}\mathrm{N} & 166 \\ <100 & 74 \\ \geq 100 \text { to }<130 & 75 \\ \geq 130 \text { to }<160 & 13 \\ \geq 160 \text { to }<190 & 3 \\ \geq 190 & 1 \\ \text { Shift in ALT from normal at baseline to worst CTC grade } \\ \mathrm{N} & 329 \\ \text { Normal } & 223 \\ \text { Grade } 1 & 91 \\ \text { Grade } 2 & 12 \\ \text { Grade } 3 & 3 \\ \text { Grade } 4 & 0 \\ \text { Shift in AST from normal at baseline to worst CTC grade } \\ \text { N } & 338 \\ \text { Normal } & 257 \\ \text { Grade } 1 & 73 \\ \text { Grade } 2 & 7 \\ \text { Grade } 3 & 1 \\ \text { Grade } 4 & 0\end{array}$

Shift in total bilirubin from normal at baseline to worst CTC grade

$\begin{array}{lc}\text { N } & 345 \\ \text { Normal } & 277 \\ \text { Grade } 1 & 55 \\ \text { Grade } 2 & 13 \\ \text { Grade } 3 & 0 \\ \text { Grade } 4 & 0 \\ \text { Shift in neutrophils from normal at baseline to worst CTC grade } \\ \mathrm{N} & 342 \\ \text { Normal } & 205 \\ \text { Grade } 1 & 51 \\ \text { Grade 2 } & 67 \\ \text { Grade 3 } & 18 \\ \text { Grade 4 } & 1 \\ \text { Shift in platelets from normal at baseline to worst CTC grade } \\ \text { N } & 341 \\ \text { Normal } & 311 \\ \text { Grade } 1 & 29 \\ \text { Grade 2 } & 1 \\ \text { Grade 3 } & 0 \\ \text { Grade } 4 & 0\end{array}$

ALT: alanine aminotransferase; AST: aspartate aminotransferase; CTC: common terminology criteria; HDL: high-density lipoprotein; IV: intravenous; LDL: low-density lipoprotein; SC: subcutaneous; TCZ: tocilizumab; TCZ-SC-mono: subcutaneous TCZ montherapy. 

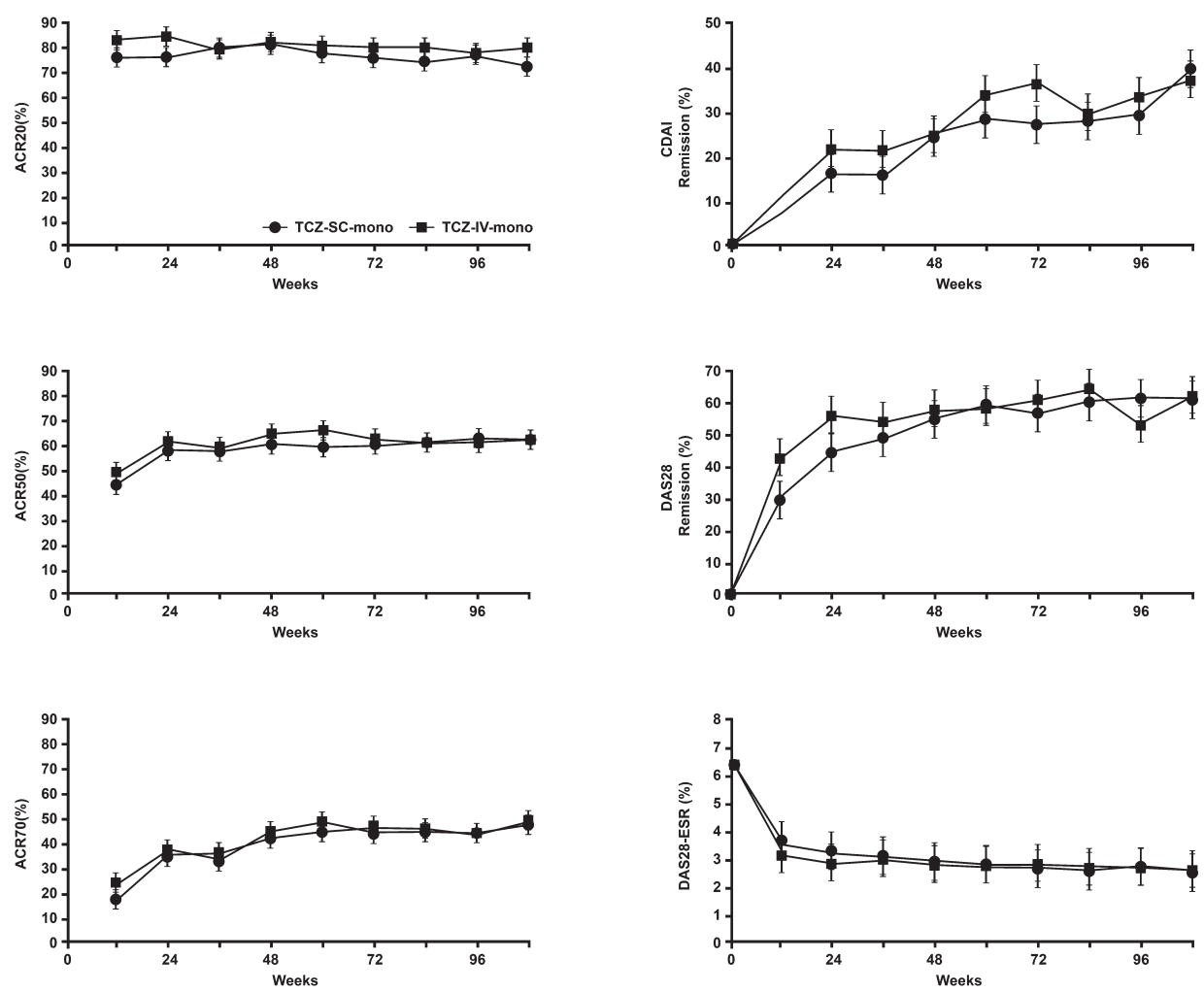

Figure 3. Efficacy of the open-label extension period (weeks 24-108) between patients who received TCZ-SC-mono or TCZ-IV-mono in the double-blind periods (weeks 0-24). American College of Rheumatology (ACR) response rate of 20\% (ACR20), 50\% (ACR50), and 70\% (ACR70), Clinical Disease Activity Index (CDAI) remission, and Disease Activity Score in 28 joints (DAS28) remission were analyzed by nonresponder imputation. DAS28 using the erythrocyte sedimentation rate (DAS28-ESR) was analyzed by last observation carried forward method. Data are presented with 95\% CI. TCZ-IV-mono: intravenous tocilizumab monotherapy; TCZ-SC-mono: subcutaneous TCZ monotherapy.

Increase and reduction of dosing interval. Twenty-four patients received TCZ-SC-mono qw; 62.5\% (15 of 24) weighed $\geq 60 \mathrm{~kg}$. The mean body weight $( \pm \mathrm{SD})$ in these patients with insufficient response was $63.0 \pm 10.8 \mathrm{~kg}$, and that of the overall patient population was $54.0 \pm 9.5 \mathrm{~kg}$, while the baseline mean BMI $( \pm$ SD) in patients with insufficient response was $24.45 \pm 4.19 \mathrm{~kg} / \mathrm{m}^{2}$ and that of the overall patient population was $21.68 \pm 3.42 \mathrm{~kg} / \mathrm{m}^{2}$. In $58.3 \%$ (14 of 24 ) of these patients, CRP values did not decrease below the institutional reference value $(<0.30 \mathrm{mg} / \mathrm{dl})$ and in $62.5 \%(15$ of 24), serum TCZ concentrations were decreased to $<1$ $\mu \mathrm{g} / \mathrm{ml}$. Twenty-four weeks after the administration interval was shortened, DAS28-ESR improved from $4.6 \pm 1.6$ to 2.3 $\pm 1.6(\mathrm{n}=20$, Figure $5 \mathrm{~A})$; and the concentration of serum TCZ [median (Q1:Q3)] increased from 0.16 (BLQ: 3.80 $\mu \mathrm{g} / \mathrm{ml})$ to $18.60(14.95: 35.70 \mu \mathrm{g} / \mathrm{ml}$; Figure $5 \mathrm{~B})$. The proportion of patients who achieved DAS28-ESR remission or low disease activity increased from $8.3 \%$ (2 of 24$)$ and $16.7 \%$ (4 of 24 ) to $70.0 \%$ (14 of 20) and $80.0 \%$ (16 of 20) at Week 24, respectively.

In contrast, dosing intervals were changed to $\mathrm{q} 3 \mathrm{w}$ for 26 patients (mean \pm SD body weight $51.5 \pm 10.6 \mathrm{~kg}$ ) who agreed to this change after achieving DAS28-ESR remission; $11.5 \%$ of these patients ( 3 of 26) weighed $\geq 60 \mathrm{~kg}$, and $92.3 \%$ (24 of 26) had serum TCZ concentrations $>1 \mu \mathrm{g} / \mathrm{ml}$ just before the TCZ q3w treatment period. Before extension of the interval, the proportion of patients who achieved DAS28-ESR remission or low disease activity was $88.5 \%$ (23 of 26) and $96.2 \%$ (25 of 26), respectively. The DAS28-ESR remission or low disease activity achievement was $78.3 \%$ (18 of 23) and $95.7 \%$ (22 of 23 ) at 24 weeks after extension of the interval (TCZ-SC-mono q3w), respectively. CRP level in all patients was maintained below the institutional normal range. The mean concentration of TCZ was maintained until 12 weeks after q3w extension of the TCZ-SC injection interval. From Week 12 to Week 24 after extension, the median (Q1:Q3) concentration of TCZ decreased from 12.35 (6.36:24.20) $\mu \mathrm{g} / \mathrm{ml}$ to 0.19 (BLQ 2.56 $\mu \mathrm{g} / \mathrm{ml}$ ), but DAS28-ESR was maintained (Figure 5C-D).

Of the 24 patients with a reduced dosing interval (TCZ-SC-mono qw), 22 patients had $82 \mathrm{AE}$ (414.8 events per $100 \mathrm{PY})$, a rate comparable to that with a normal dosing interval of TCZ-SC-mono q2w (538.0 events per $100 \mathrm{PY}$ ). Four SAE were observed in the patients who received

Personal non-commercial use only. The Journal of Rheumatology Copyright @ 2015 . All rights reserved. 
A

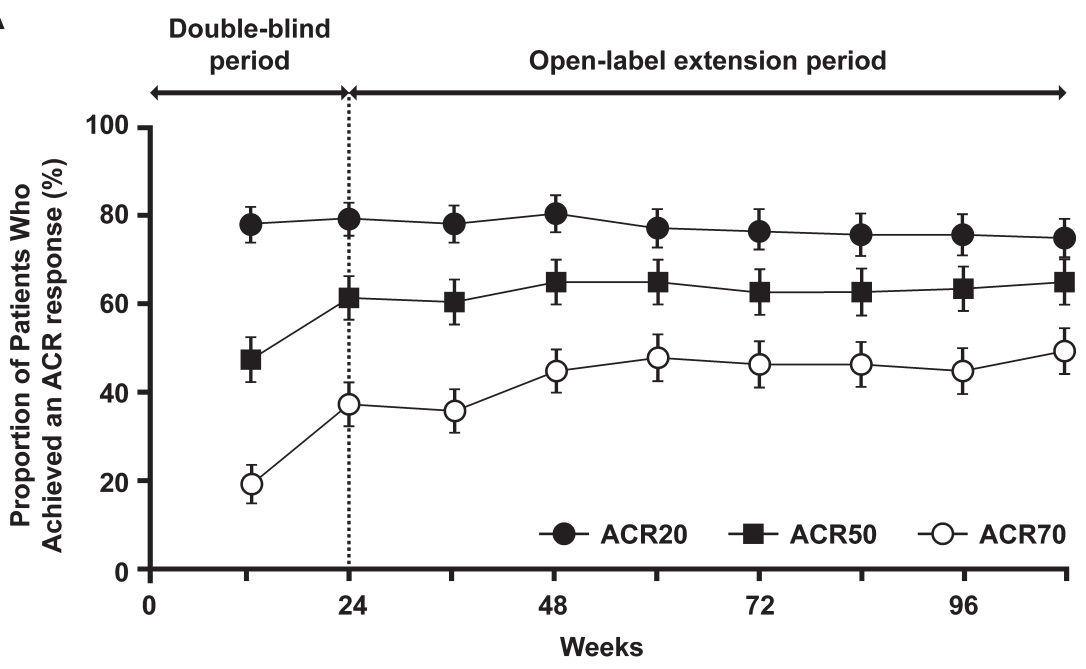

B

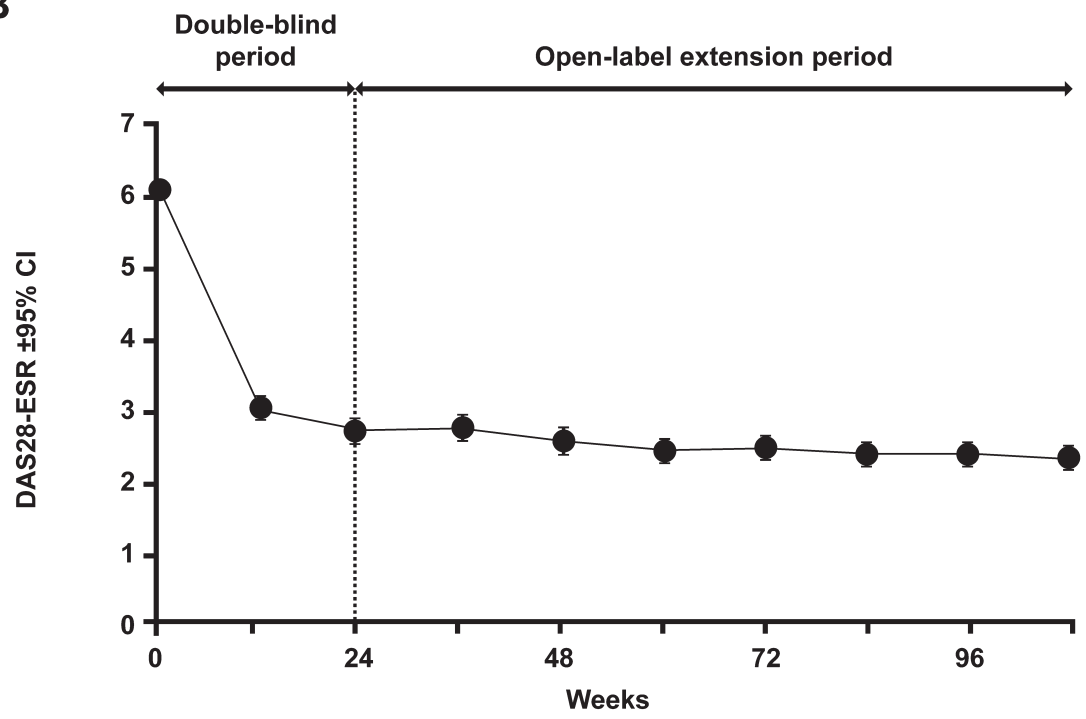

C

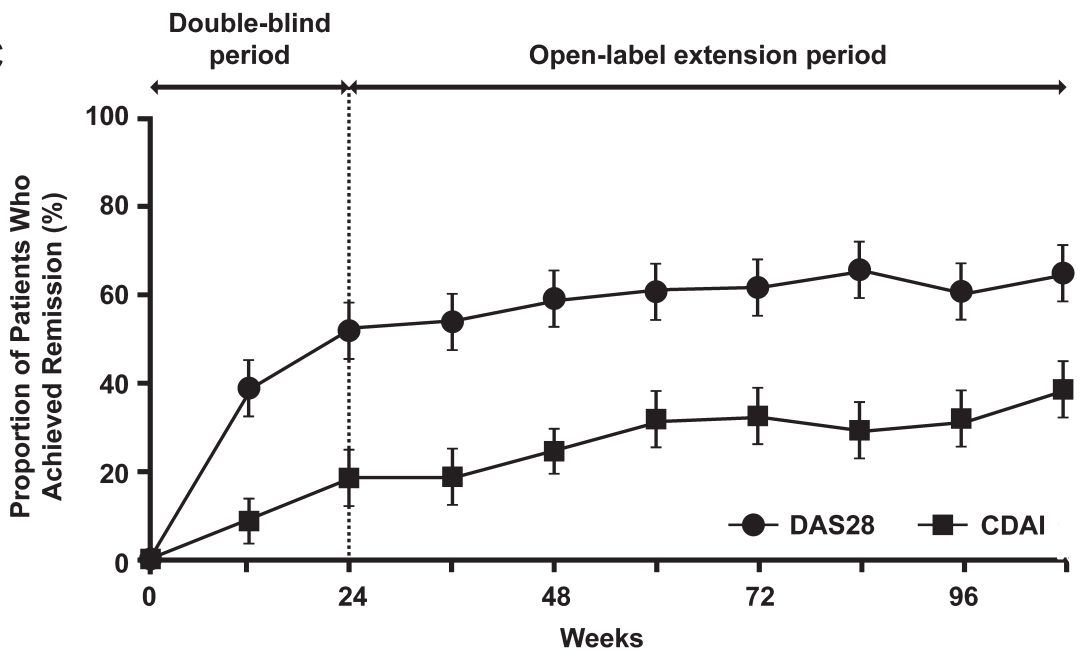

Figure 4. Maintenance of clinical response during longterm treatment with subcutaneous tocilizumab monotherapy. A. Proportions of patients who achieved an American College of Rheumatology (ACR) response rate of $20 \%$ (ACR20), $50 \%$ (ACR50), and 70\% (ACR70). B. Disease Activity Score in 28 joints using the erythrocyte sedimentation rate (DAS28-ESR). C. Proportions of patients who achieved clinical remission [DAS28-ESR $<2.6$ and Clinical Disease Activity Index $(\mathrm{CDAI}) \leq 2.8]$. For missing data, nonresponder imputation was applied to response data (ACR20/50/70), DAS28 remission, and CDAI remission, while last observation carried forward was applied to continuous data (DAS28). Data are presented with $95 \%$ CI. Both double-blind (Day 1 to Week 24) and longterm extension (weeks 24-108) data are presented. 
A

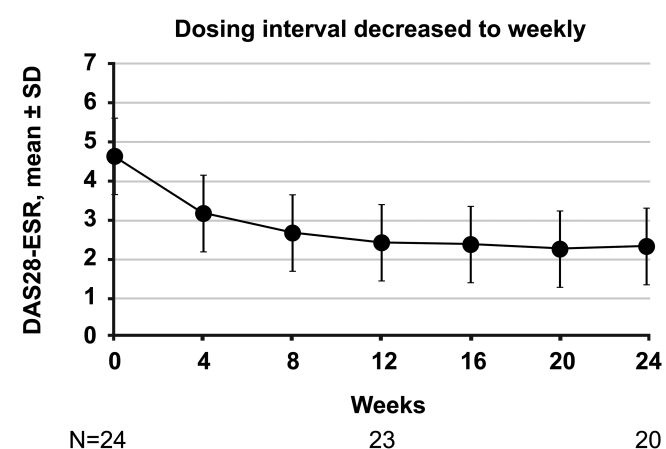

B

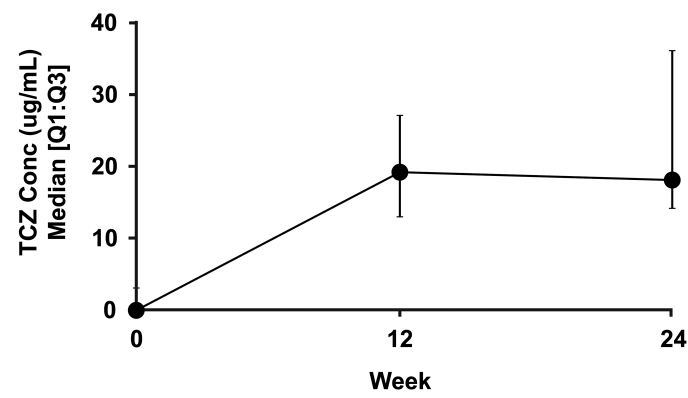

C

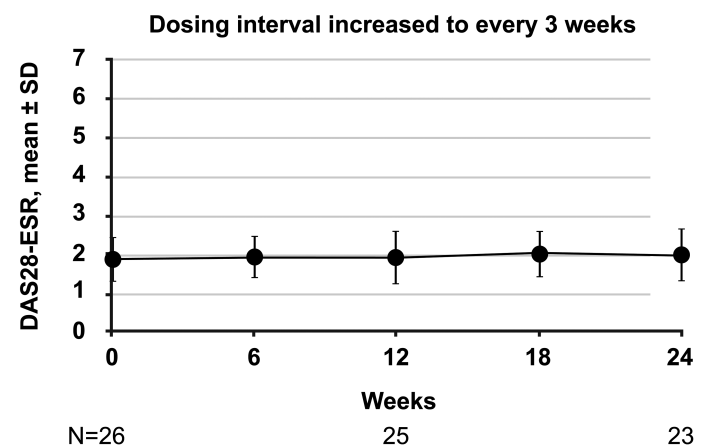

D

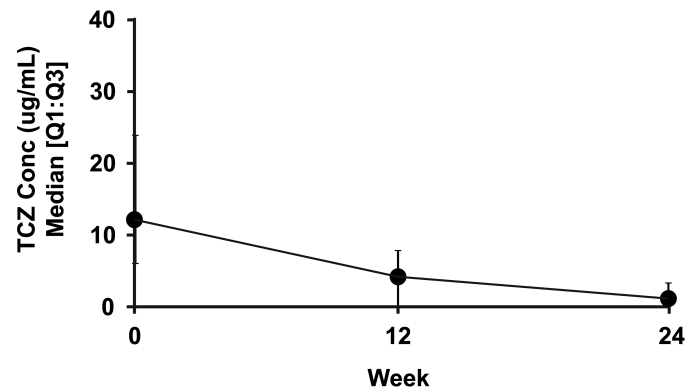

Figure 5. Mean 28-joint Disease Activity Score (DAS28-ESR) and the serum concentration (Conc) of tocilizumab (TCZ) observed after changing the dosing interval to weekly (panels A, B) in inadequate response to subcutaneous TCZ monotherapy every 2 weeks (TCZ-SC-mono q2w) or every 3 weeks (panels C, D) after achieving remission by TCZ-SC-mono q2w. Reasons for the patients' withdrawal from interval shortening were adverse event $(n=1)$, low efficacy $(n=1)$, and other $(n=2)$. DAS28 are expressed as mean \pm SD and TCZ concentrations are expressed as the median with the first and third quartile. ESR: erythrocyte sedimentation rate.

TCZ-SC-mono qw. After the dosing interval was decreased from TCZ-SC-mono $\mathrm{q} 2 \mathrm{w}$ to $\mathrm{qw}$, the proportion of patients with AE with increased triglycerides or ALT or decreased platelets or neutrophils did not increase.

\section{DISCUSSION}

The OLE period of the MUSASHI study evaluated the longterm safety and efficacy of TCZ-SC-mono $162 \mathrm{mg} \mathrm{q} 2 \mathrm{w}$ in Japanese patients with RA. These results confirmed our original findings at 24 weeks and demonstrated that TCZ-SC-mono provided a sustained favorable safety and efficacy profile. The safety profile of TCZ-SC-mono was observed in previous studies of TCZ-IV and was associated with a risk/benefit ratio that supports its use in patients with RA $^{14,19,20}$. The proportions of patients who achieved an ACR20/50/70 response, low disease activity (DAS28-ESR $\leq$ 3.2), or remission (DAS28-ESR < 2.6) at Week 24 were maintained over the 108 weeks. Retention rates were similar to those seen in longterm studies of TCZ-IV ${ }^{19,20}$.

The longterm safety profile of TCZ-SC-mono was determined during the 108 weeks of our study. The treatment was generally well tolerated, and the associated AE profile was consistent with the known and well-established safety profile of TCZ. Although the short-term safety profiles of TCZ-SC-mono and TCZ-IV-mono were similar, there is no direct comparison of the longterm safety profiles of TCZ-SC-mono and TCZ-IV-mono. Because half the patients received TCZ-IV-mono for 24 weeks and then switched to TCZ-SC-mono for 84 weeks, we can only indirectly compare the longterm safety of TCZ-SC-mono and TCZ-IV-mono. In comparing the TCZ-SC-mono data from our study to the cumulative safety data from TCZ-IV phase III trials ${ }^{20}$, we saw no additional concerns about TCZ-SC-mono. Future direct comparison of longterm safety of TCZ-SC-mono and TCZ-IV-mono will be necessary.

Maintenance of longterm efficacy is a key consideration in the management of RA. From Week 24 to Week 108, there was a gradual increase in the proportion of patients who achieved an ACR20/50/70 response, an improvement of category in ACR response, and a clinical response as evaluated by DAS28-ESR. Overall, after 108 weeks of exposure, there was no attenuation of the therapeutic

Personal non-commercial use only. The Journal of Rheumatology Copyright (c) 2015. All rights reserved. 
response. In our study, the efficacy of TCZ-SC-mono was analyzed by nonresponder imputation or LOCF method because most patients had discontinued owing to an insufficient therapeutic response. However, fewer than $5 \%$ of patients discontinued because of an insufficient response. No clinical intolerance during longterm administration of TCZ-SC-mono was observed.

We evaluated adjustment of the administration interval of TCZ-SC in various situations in a limited number of patients (open-label setting). Previous studies had demonstrated that maintenance of serum trough concentration of TCZ is important for sufficient maintenance of efficacy ${ }^{18}$. Shortening of the administration interval (qw administration of TCZ-SC) was evaluated in patients with inadequate response to TCZ-SC-mono q2w. Shortening of the TCZ-SC-mono q2w dosing interval to qw improved DAS28-ESR and increased the proportion of patients who achieved clinical remission. In most of these patients, TCZ-SC-mono qw enhanced the efficacy with an increased serum TCZ concentration, suggesting that inadequate clinical response was due to insufficient maintenance of serum TCZ concentrations, and that shortening the dosing interval to qw would be an effective solution for patients who still have high disease activity after receiving TCZ-SC-mono $\mathrm{q} 2 \mathrm{w}$. Extension of the administration interval ( $\mathrm{q} 3 \mathrm{w}$ administration of TCZ-SC) was evaluated in patients who achieved clinical remission by TCZ-SC-mono $\mathrm{q} 2 \mathrm{w}$. In these patients, TCZ-SC-mono $\mathrm{q} 3 \mathrm{w}$ maintained efficacy without CRP elevation for $\geq 6$ months. These results suggest that extension of the administration interval may be possible in good responders to TCZ. Further studies will help validate the results that were shown in this small patient population.

The reasons for insufficient response to TCZ-SC have not been thoroughly elucidated. The main cause seems to be lower serum concentration of TCZ. Because TCZ-SC-mono was administered as a single dose regardless of body weight, low efficacy may have occurred in patients with higher body weight and/or with higher BMI; they received a relatively lower dosage. As previously reported for the MUSASHI study, the TCZ mean serum trough concentrations were lower in patients with high BMI, and the effectiveness of TCZ-SC-mono may be lower in patients with high $\mathrm{BMI}^{16}$. In other reports about patients with RA, a high BMI has been associated with decreased clinical responses to treatments including biologics ${ }^{21,22,23}$. In addition, the BREVACTA study ${ }^{24}$ evaluated the effectiveness of a biweekly dosing interval for TCZ-SC combined with MTX, as stratified by body weight. Those results ${ }^{16,24}$ suggested that shortening of the TCZ-SC treatment interval may be a good option to improve disease activity in patients with higher body weight. Future studies will be necessary to uncover the reasons for the insufficient response to TCZ-SC-mono, effect of dosing interval shortening, and the relation to the serum trough concentration, because our present study was small.
In 23 of 26 patients who achieved remission, efficacy was maintained after extension of the injection interval ( $\mathrm{q} 3 \mathrm{w})$. Although the concentration of TCZ was decreased, the small amount of TCZ may have been enough to neutralize IL-6 function in patients who achieved remission because IL-6 production was decreased. The concentration of TCZ was decreased from 12 weeks after the interval extension through 36 weeks (data not shown). Therefore, some patients for whom the dosing interval is changed to q3w may need to return to the $\mathrm{q} 2 \mathrm{w}$ dosing interval.

A limitation of this study is that the design had a double-blind period with patients receiving TCZ-IV-mono or TCZ-SC-mono followed by an OLE period of patients only receiving TCZ-SC-mono. Therefore, in half of patients who were enrolled from TCZ-IV after 24 weeks, the safety and efficacy of TCZ-SC-mono were not assessed for the entire 108 weeks. However, there were no differences in the efficacy and safety between TCZ-IV-mono and TCZ-SC-mono at Week $24^{16}$ in the double-blind period, nor any differences in efficacy and safety between TCZ-IV-mono and TCZ-SC- mono at Week 108 in our study. Additional longterm data from studies with TCZ-SC-mono will confirm the efficacy and safety observed in our study and will provide further information about the longterm risk/benefit ratio.

The safety and efficacy results of this 108-week longterm extension study in Japanese patients with RA are consistent with those in previously published 24-week TCZ-SC-mono studies. It was determined that TCZ-SC-mono demonstrated a favorable risk benefit profile in this cohort of patients because it was well tolerated and the therapeutic responses over time were not attenuated.

\section{ACKNOWLEDGMENT}

The authors thank the patients for participating.

\section{REFERENCES}

1. Singh JA, Furst DE, Bharat A, Curtis JR, Kavanaugh AF, Kremer JM, et al. 2012 update of the 2008 American College of Rheumatology recommendations for the use of disease-modifying antirheumatic drugs and biologic agents in the treatment of rheumatoid arthritis. Arthritis Care Res 2012;64:625-39.

2. Smolen JS, Landewé R, Breedveld FC, Buch M, Burmester G, Dougados $\mathrm{M}$, et al. EULAR recommendations for the management of rheumatoid arthritis with synthetic and biological disease-modifying antirheumatic drugs: 2013 update. Ann Rheum Dis 2014;73:492-509.

3. Scott DL. Biologics-based therapy for the treatment of rheumatoid arthritis. Clin Pharmacol Ther 2012;91:30-43

4. Barton JL. Patient preferences and satisfaction in the treatment of rheumatoid arthritis with biologic therapy. Patient Prefer Adherence 2009;3:335-44.

5. Chilton F, Collett RA. Treatment choices, preferences and decision-making by patients with rheumatoid arthritis. Musculoskeletal Care 2008;6:1-14.

6. Williams EL, Edwards CJ. Patient preferences in choosing anti-TNF therapies-R1. Rheumatology 2006;45:1575-6.

7. Ogata A, Hirano T, Hishitani Y, Tanaka T. Safety and efficacy of tocilizumab for the treatment of rheumatoid arthritis. Clin Med

Personal non-commercial use only. The Journal of Rheumatology Copyright @ 2015. All rights reserved. 
Insights Arthritis Musculoskelet Disord 2012;5:27-42.

8. Nishimoto N, Hashimoto J, Miyasaka N, Yamamoto K, Kawai S, Takeuchi T, et al. Study of active controlled monotherapy used for rheumatoid arthritis, an IL-6 inhibitor (SAMURAI): evidence of clinical and radiographic benefit from an $\mathrm{x}$ ray reader-blinded randomised controlled trial of tocilizumab. Ann Rheum Dis 2007;66:1162-7.

9. Genovese MC, McKay JD, Nasonov EL, Mysler EF, da Silva NA, Alecock E, et al. Interleukin-6 receptor inhibition with tocilizumab reduces disease activity in rheumatoid arthritis with inadequate response to disease-modifying antirheumatic drugs: the tocilizumab in combination with traditional disease-modifying antirheumatic drug therapy study. Arthritis Rheum 2008;58:2968-80.

10. Emery P, Keystone E, Tony HP, Cantagrel A, van Vollenhoven R, Sanchez A, et al. IL-6 receptor inhibition with tocilizumab improves treatment outcomes in patients with rheumatoid arthritis refractory to anti-tumour necrosis factor biologicals: results from a 24-week multicentre randomised placebo-controlled trial. Ann Rheum Dis 2008;67:1516-23.

11. Smolen JS, Beaulieu A, Rubbert-Roth A, Ramos-Remus C, Rovensky J, Alecock E, et al. Effect of interleukin-6 receptor inhibition with tocilizumab in patients with rheumatoid arthritis (OPTION study): a double-blind, placebo-controlled, randomised trial. Lancet 2008;371:987-97.

12. Nishimoto N, Miyasaka N, Yamamoto K, Kawai S, Takeuchi T, Azuma J, et al. Study of active controlled tocilizumab monotherapy for rheumatoid arthritis patients with an inadequate response to methotrexate (SATORI): significant reduction in disease activity and serum vascular endothelial growth factor by IL-6 receptor inhibition therapy. Mod Rheumatol 2009;19:12-9.

13. Jones G, Sebba A, Gu J, Lowenstein MB, Calvo A, Gomez-Reino $\mathrm{JJ}$, et al. Comparison of tocilizumab monotherapy versus methotrexate monotherapy in patients with moderate to severe rheumatoid arthritis: the AMBITION study. Ann Rheum Dis 2010;69:88-96.

14. Kremer JM, Blanco R, Brzosko M, Burgos-Vargas R, Halland AM, Vernon E, et al. Tocilizumab inhibits structural joint damage in rheumatoid arthritis patients with inadequate responses to methotrexate: results from the double-blind treatment phase of a randomized placebo-controlled trial of tocilizumab safety and prevention of structural joint damage at one year. Arthritis Rheum 2011;63:609-21.

15. Ohta S, Tsuru T, Terao K, Mogi S, Suzaki M, Shono E, et al. Mechanism-based approach using a pharmacokinetic/biomarker response to evaluate tocilizumab subcutaneous injection in patients with rheumatoid arthritis with an inadequate response to synthetic DMARDs (MATSURI study). J Clin Pharmacol 2014;54:109-19.

16. Ogata A, Tanimura K, Sugimoto T, Inoue H, Urata Y, Matsubara T, et al. A phase 3 study of the efficacy and safety of subcutaneous versus intravenous tocilizumab monotherapy in patients with rheumatoid arthritis (MUSASHI). Arthritis Care Res 2014; 66:344-54

17. Stubenrauch K, Wessels U, Birnboeck H, Ramirez F, Jahreis A, Schleypen J. Subset analysis of patients experiencing clinical events of a potentially immunogenic nature in the pivotal clinical trials of tocilizumab for rheumatoid arthritis: evaluation of an antidrug antibody ELISA using clinical adverse event-driven immunogenicity testing. Clin Ther 2010;32:1597-609.

18. Nishimoto N, Terao K, Mima T, Nakahara H, Takagi N, Kakehi T. Mechanisms and pathologic significances in increase in serum interleukin-6 (IL-6) and soluble IL-6 receptor after administration of an anti-IL-6 receptor antibody, tocilizumab, in patients with rheumatoid arthritis and Castleman disease. Blood 2008; 112:3959-64.
19. Nishimoto N, Miyasaka N, Yamamoto K, Kawai S, Takeuchi T, Azuma J. Long-term safety and efficacy of tocilizumab, an anti-IL-6 receptor monoclonal antibody, in monotherapy, in patients with rheumatoid arthritis (the STREAM study): evidence of safety and efficacy in a 5-year extension study. Ann Rheum Dis 2009; 68:1580-4.

20. Genovese MC, Rubbert-Roth A, Smolen JS, Kremer J, Khraishi M, Gomez-Reino J, et al. Longterm safety and efficacy of tocilizumab in patients with rheumatoid arthritis: a cumulative analysis of up to 4.6 years of exposure. J Rheumatol 2013;40:768-80.

21. Gremese E, Carletto A, Padovan M, Atzeni F, Raffeiner B, Giardina $\mathrm{AR}$, et al. Obesity and reduction of the response rate to anti-tumor necrosis factor $\alpha$ in rheumatoid arthritis: an approach to a personalized medicine. Arthritis Care Res 2013;65:94-100.

22. Heimans L, van den Broek M, le Cessie S, Siegerink B, Riyazi N, $\mathrm{Han} \mathrm{KH}$, et al. Association of high body mass index with decreased treatment response to combination therapy in recent-onset rheumatoid arthritis patients. Arthritis Care Res 2013;65:1235-42.

23. Klaasen R, Wijbrandts CA, Gerlag DM, Tak PP. Body mass index and clinical response to infliximab in rheumatoid arthritis. Arthritis Rheum 2011;63:359-64.

24. Kivitz A, Olech E, Borofsky M, Zazueta BM, Navarro-Sarabia F, Radominski SC, et al. Subcutaneous tocilizumab versus placebo in combination with disease-modifying antirheumatic drugs in patients with rheumatoid arthritis. Arthritis Care Res 2014;66:1653-61.

\section{APPENDIX.}

List of study collaborators: Members of the MUSASHI Study Group: K. Amano (Saitama Medical Center), T. Atsumi (Hokkaido University), H. Dobashi (Kagawa University), T. Fukuda (Kurume University Medical Center), J. Hashimoto (Osaka University), Y. Hirabayashi (Hikarigaoka Spellman Hospital), M. Inaba (Osaka City University), M. Inoo (Utazu Hama Clinic), H. Inoue (Inoue Hospital), Y. Ishigatsubo (Yokohama City University), N. Ishiguro (Nagoya University), T. Ishii (Tohoku University), M. Iwahashi (Higashihiroshima Memorial Hospital), M. Kai (National Hospital Organization Mie Chuo Medical Center), T. Kasama (Showa University), D. Kawabata (Kyoto University), S. Kawai (Toho University), A. Kawakami (Nagasaki University), D. Kida (National Hospital Organization Nagoya Medical Center), H. Kohsaka (Tokyo Medical and Dental University), T. Koike (Osaka City University), M. Kondo (Kondo Clinic), T. Matsubara (Matsubara Mayflower Hospital), R. Matsumura (National Hospital Organization Chiba-East), S. Minota (Jichi Medical University), H. Miyahara (National Hospital Organization Kyushu Medical Center), T. Miyamoto (Seirei Hamamatsu General Hospital), M. Mukai (Sapporo City General Hospital), Y. Munakata (Munakata Yasuhiko Clinic), A. Murasawa (Niigata Rheumatic Center), N. Nishimoto (CRENT Clinic), N. Ogawa (Hamamatsu University), S. Ohta (Taga General Hospital), T. Ojima (Fukui General Hospital), Y. Saeki (National Hospital Organization Osaka Minami Medical Center), H. Sano (Hyogo College of Medicine), K. Shi (Osaka University), E. Shono (Shono Rheumatic Clinic), E. Suematsu (National Hospital Organization Kyushu Medical Center), K. Sugimoto (Fukui General Hospital), T. Sugimoto (National Hospital Organization Shimoshizu), T. Sumida (Tsukuba University), H. Takahashi (Sapporo Medical University), K. Takasugi (Dohgo Spa Hospital), T. Takeuchi (Keio University), S. Tamaki (National Hospital Organization Mie Chuo Medical Center), T. Tanaka (Osaka University), Y. Tanaka (University of Occupational and Environmental Health), K. Tanimura (Hokkaido Medical Center), S. Tohma (National Hospital Organization Sagamihara), H. Tsukamoto (Kyushu University), Y. Ueki (Sasebo Chuo Hospital), Y. Urata (Seihoku Central Hospital), K. Yamamoto (University of Tokyo), H. Yamanaka (Tokyo Women's Medical University), and H. Yoshifuji (Kyoto University). 